\title{
The influence of selected fungicides and soil extracts on the growth of entomopathogenic fungus Metarhizium anisopliae
}

\author{
Wpływ wybranych fungicydów oraz wyciągów glebowych \\ na wzrost owadobójczego grzyba Metarhizium anisopliae
}

\author{
Cezary Tkaczuk, Anna Majchrowska-Safaryan, Ryszard Miętkiewski
}

\section{Summary}

The basic method of pest control in crops is still the use of pesticides that are building up in the soil and are the cause of changes in microbial activity, usually in the quantitative composition of the soil microflora. The aim of this study was to investigate the effect of three selected fungicides and soil extracts obtained from the sandy and organic soil on the growth of entomopathogenic fungus Metarhizium anisopliae in vitro. Among the tested fungicides the strongest growth inhibition of M. anisopliae caused Score 250 EC formulation, and relatively least Antracol 70 WG. The results indicate that the addition of soil extracts to the culture medium with fungicides increased the inhibitory action on the growth of the fungus. Extract from organic soil added to the culture medium with fungicides strongly inhibited the growth of $M$. anisopliae colonies than an extract obtained from the sandy soil.

Key words: fungicides, soil extracts, entomopathogenic fungus, Metarhizium anisopliae

\section{Streszczenie}

Podstawową metodą zwalczania agrofagów w uprawach roślin jest stosowanie pestycydów, które kumulując się w glebach stają się przyczyną zmiany aktywności mikrobiologicznej, najczęściej w składzie ilościowym mikroflory glebowej. Celem pracy było zbadanie wpływu trzech wybranych fungicydów oraz wyciągów glebowych otrzymanych z gleby piaszczystej i organicznej, na wzrost owadobójczego grzyba Metarhizium anisopliae w warunkach in vitro. Spośród badanych fungicydów wzrost M. anisopliae najsilniej hamował preparat Score 250 EC, a stosunkowo najsłabiej Antracol 70 WG. Uzyskane wyniki wskazują, iż dodanie do podłoża hodowlanego z fungicydami wyciągów glebowych wpłynęło na zwiększenie ich inhibicyjnego działania na wzrost grzyba. Wyciąg z gleby organicznej dodany do podłoża hodowlanego z fungicydami silniej hamował wzrost kolonii M. anisopliae niż wyciąg otrzymany z gleby piaszczystej.

Słowa kluczowe: fungicydy, wyciągi glebowe, grzyb owadobójczy, Metarhizium anisopliae

\author{
Uniwersytet Przyrodniczo-Humanistyczny w Siedlcach \\ Zakład Ochrony Roślin \\ Prusa 14, 08-110 Siedlce \\ tkaczuk@uph.edu.pl
}




\section{Wstęp / Introduction}

Grzyby entomopatogeniczne to gatunki mikroorganizmów, które posiadają zdolność do infekowania owadów, a ich rozwój prowadzi do zakłóceń procesów fizjologicznych u gospodarzy i w końcowym efekcie do ich śmierci. Głównym rezerwuarem grzybów owadobójczych jest gleba (Ignoffo i wsp. 1978; Ferron 1981; Bajan i Kmitowa 1997; Tkaczuk i wsp. 2012), będąca jednocześnie miejscem bytowania wielu szkodników roślin. Występowanie oraz patogeniczność tych grzybów w glebie uzależniona jest od wielu czynników oddziałujących na środowisko glebowe, m.in.: rodzaju gleby, temperatury, wilgotności oraz stosowanych zabiegów ochrony roślin (Vänninen i wsp. 2000; Tkaczuk 2008; Krysa i wsp. 2012; Tkaczuk i wsp. 2012). Zaliczane do anamorf workowców (Ascomycota, Hypocreales) grzyby z rodzaju Metarhizium, ze względu na łatwość ich hodowli na tanich podłożach oraz formulacji i aplikacji są często wykorzystywane w walce ze szkodnikami w postaci biopreparatów (Prior i Greathead 1989; Tkaczuk i wsp. 2012).

Podstawową metodą zwalczania agrofagów w uprawie roślin wciąż jednak pozostaje stosowanie pestycydów. Środki ochrony roślin zalegające w środowisku glebowym mogą negatywnie wpływać na organizmy glebowe, powodując modyfikacje w ich składzie ilościowym i jakościowym (Megharaj i wsp. 2000). Z jednej strony pestycydy są silnie toksyczne dla wielu mikroorganizmów glebowych. Wnikając do ich komórek zakłócają procesy metaboliczne powodując śmierć wrażliwej części populacji. Z drugiej strony mikroorganizmy niewrażliwe, mogą wykorzystywać składniki pokarmowe uwalniane do gleby w trakcie procesów mineralizacji obumarłych organizmów, co wpływa na zwiększenie ich liczby (Das i wsp. 2005).

Badania prowadzone $\mathrm{w}$ warunkach laboratoryjnych wskazują na negatywny wpływ środków ochrony roślin na grzyby entomopatogeniczne. Mogą one ograniczać zarówno wzrost, zarodnikowanie, kiełkowanie zarodników, jak i patogeniczność tych grzybów. Bajan i Kmitowa (1997), Tkaczuk (2001, 2008), Andalo i wsp. (2004), Li i wsp. (2004), Tkaczuk i wsp. (2012) stwierdzili stosunkowo małą szkodliwość insektycydów i średni inhibicyjny wpływ herbicydów na wzrost grzybów owadobójczych w warunkach in vitro. Najbardziej negatywnie na te mikroorganizmy wpływają fungicydy, a ich oddziaływanie w dużym stopniu uzależnione jest od substancji czynnej oraz gatunku grzyba (Majchrowicz i Poprawski 1993; Li i Holdom 1994; Loureiro i wsp. 2002; Fiedler i Sosnowska 2011; Tkaczuk i wsp. 2012). Ograniczanie kiełkowania zarodników grzybów owadobójczych przez stosowane w środowisku pestycydy, odbija się niekorzystnie na przebiegu procesu infekcji i rozwoju choroby w populacji szkodnika. Według Bouciasa i wsp. (1988) kontakt zarodników konidialnych z substancjami chemicznymi, w tym $\mathrm{z}$ pestycydami, może powodować neutralizację ładunku elektrostatycznego, zniszczenie warstwy śluzu na powierzchni zarodników grzybów owadobójczych, a przez to ograniczać intensywność procesu kiełkowania i infekcji ciała gospodarza.

Stosowanie biopreparatów grzybowych w integrowanych programach ochrony upraw przed szkodnikami wymaga określenia wrażliwości grzybów owadobójczych na pestycydy, istotną bowiem cechą oprócz ich wysokiej skuteczności, powinna być również selektywność działania w stosunku do mikroorganizmów pożytecznych.

Jak już wspomniano, stosunkowo dużo badań poświęcono wpływowi środków ochrony roślin na grzyby entomopatogeniczne $\mathrm{w}$ warunkach in vitro, natomiast jest bardzo mało doniesień na temat wpływu pestycydów na występowanie i rozwój tych patogenów owadów w glebie w warunkach polowych (Miętkiewski i wsp. 1997; Mochi i wsp. 2005; Tkaczuk 2008).

Próbą poznania potencjalnych trój-troficznych oddziaływań, jakie mogą zachodzić w układzie grzyb-fungicydygleba były podjęte badania, których celem było zbadanie wpływu trzech wybranych fungicydów: Dithane Neo Tec $75 \mathrm{WG}$, Score 250 EC i Antracol 70 WG oraz wyciagów glebowych otrzymanych z gleby piaszczystej i organicznej, na wzrost owadobójczego grzyba Metarhizium anisopliae $\mathrm{w}$ warunkach in vitro.

\section{Materiały i metody / Materials and methods}

W warunkach laboratoryjnych zbadano wpływ trzech fungicydów: Antracol $70 \mathrm{WG}$ (propineb), Dithane Neo Tec 75 WG (mankozeb) i Score 250 EC (difenkonazol) oraz dwóch wyciagów glebowych na wzrost kolonii owadobójczego grzyba M. anisopliae (Metschn.) Sorokin. Szczep grzyba został wyizolowany za pomocą metody owadów pułapkowych (Galleria mellonella) z gleby łąkowej. Wyciąi glebowe sporządzono z dwóch gatunków gleb. Obie próby glebowe pobrano pod koniec listopada 2008 roku. Pierwsza gleba pochodziła $\mathrm{z}$ pola uprawnego, na którym uprawiano żyto i była to gleba piaszczysta (piasek gliniasty lekki, wartość $\mathrm{pH}=5,6$ ), natomiast druga gleba była organiczna i pochodziła $\mathrm{z}$ łąki (wartość $\mathrm{pH}=6,2$ ). Wyciag otrzymany z gleby piaszczystej oznaczono jako wyciąg I, a z gleby organicznej jako wyciąg II.

Wyciagi glebowe przygotowano w następujący sposób: $4 \mathrm{~kg}$ gleby po uprzednim przesianiu przez sito rozpuszczono w 4 litrach wody sterylizowanej. Roztwór glebowy gotowano przez 45 minut, a następnie przesączono przez sączki. Po przesączeniu objętość roztworu uzupełniono do 4 litrów. Do każdego roztworu glebowego oraz wariantu kontrolnego (czysty roztwór wodny) dodawano podłoże Sabourauda. Do podłoża o temperaturze około $50-60^{\circ} \mathrm{C}$ wprowadzano odpowiednie dawki fungicydów. Kolejne stężenia preparatów w podłożu uzyskano metodą rozcieńczeń. Fungicydy dodawano do podłoża w następujących dawkach: A - zalecana dawka polowa fungicydu; B - dawka 10-krotnie niższa od zalecanej dawki polowej; C - dawka 100-krotnie niższa od zalecanej.

Przygotowane podłoża hodowlane rozlano do szalek Petriego i po upływie 24 godzin inokulowano punktowo grzybem $M$. anisopliae. Szalki umieszczono w inkubatorach $\mathrm{w}$ temperaturze $22-23^{\circ} \mathrm{C}$. Obserwacje wzrostu grzybni prowadzono przez 20 dni w odstępach 5-dniowych mierząc średnicę kolonii. Każdą kombinację wykonano w pięciu powtórzeniach. W doświadczeniu kontrolę stanowiły kultury grzyba rosnące na czystym podłożu Sabourauda. Wzrost kolonii grzyba obserwowano również na 
podłożach zawierających jedynie wyciagi glebowe bez dodatku fungicydów. Wyniki przedstawiono jako wielkość średnicy kolonii i wyrażono $\mathrm{w}$ procentach $\mathrm{w}$ stosunku do kontroli.

\section{Wyniki i dyskusja / Results and discussion}

Badane fungicydy w sposób zróżnicowany wpłynęły na wzrost na podłożu hodowlanym kolonii grzyba $M$. anisopliae, w zależności od zastosowanego preparatu, a także jego koncentracji. Prowadząc obserwację rozwoju grzyba na czystym podłożu Sabourauda oraz podłożu Sabourauda z dodatkiem samych wyciagów glebowych stwierdzono, że ich dodatek w sposób nieznaczny stymuluje jego wzrost. W przypadku dodania wyciagu I (gleba piaszczysta) kolonie grzyba były większe średnio o $4,8 \%$, a w przypad$\mathrm{ku}$ wyciagu II (gleba organiczna) o 8,4\% w stosunku do kultur rosnących na czystym podłożu hodowlanym. Potwierdził to w swoich badaniach Tkaczuk (2008) dodając do podłoży hodowlanych wyciagi glebowe $\mathrm{z}$ różnych wariantów wieloletniego nawożenia organicznego. Stwierdził, że wyciagi glebowe z poletek nawożonych obornikiem (szczególnie najwyższą dawką obornika) w istotny sposób zwiększyły przyrost kolonii grzybów owadobójczych w porównaniu z kontrolą. Należy przypuszczać, że była to reakcja grzybów na wzrastającą w podłożu zawartość węgla i azotu, a więc pierwiastków wchodzących w skład frakcji organicznej gleby, które stanowiły dla nich dodatkowe źródło substancji pokarmowych.

Najbardziej inhibicyjne działanie na wzrost kolonii M. anisopliae miał fungicyd Score 250 EC. Na pożywce $\mathrm{z}$ zalecaną dawką fungicydu (A) oraz $\mathrm{z}$ dodatkiem wyciagu I i II nie stwierdzono wzrostu kolonii tego grzyba. Również bez dodatku wyciągów glebowych fungicyd w dawce zalecanej (A) całkowicie uniemożliwił wzrost patogena na pożywce. $\mathrm{Na}$ podłożu $\mathrm{z}$ fungicydem Score $250 \mathrm{EC}$ w dawce 10-krotnie niższej od zalecanej (B), bez dodatku wyciągu glebowego, grzyb rozpoczął swój rozwój po 10 dniach od momentu inokulacji pożywki, natomiast po 20 dniach osiąnął 48,5\% wielkości kontrolnej. Przy stężeniu 100-krotnie niższym (C) niż zalecane, kolonie grzyba osiagnęły 59,8\% w stosunku do kontroli (tab. 1, rys. 1).

Dodanie do podłoża wyciagu I przy dawce fungicydu B zahamowało rozwój badanego grzyba. Kolonia zaczęła rozwijać się po 10 dniach od inokulacji, a w końcowej fazie czyli po 20 dniach hodowli osiagnęła 40,4\% wielkości kontrolnej. Na podłożu hodowlanym $\mathrm{z}$ dodatkiem fungicydu Score 250 EC w dawce 100-krotnie niższej od zalecanej (C), kolonie $M$. anisopliae w 20 dniu hodowli osiągnęły 59,8\% wielkości kolonii kontrolnych. Dodanie do podłoża $\mathrm{z}$ fungicydem obu wyciagów glebowych nie wpłynęło w sposób istotny na wielkość kolonii grzyba (tab. 1, rys. 1). Tkaczuk i wsp. (2012) stwierdzili, że fungicydy najsilniej hamowały wzrost i proces kiełkowania zarodników grzyba Beauveria bassiana ze wszystkich testowanych $\mathrm{w}$ doświadczeniu preparatów, a szczególnie toksyczne działanie wykazały środki: Topsin M i Score 250 EC.

Fungicyd Dithane Neo Tec 75 WG dodany do podłoża hodowlanego (bez wyciągów glebowych) w dawce zaleca- nej (A) istotnie hamował wzrost kolonii grzyba, które po 20 dniu hodowli osiagnęły $20,6 \%$ wzrostu kolonii kontrolnych (rys. 2). Dodanie do podłoża hodowlanego zawierającego fungicyd w dawce zalecanej wyciagu glebowego II spowodowało jeszcze silniejsze ograniczenie wzrostu grzyba. Kolonie $M$. anisopliae w 20 dniu obserwacji osiagnęły wielkość 9,5\% w stosunku do kontroli, a więc ich średnica była mniejsza o ponad $50 \%$ w porównaniu $\mathrm{z}$ koloniami grzyba rosnącymi na pożywce $\mathrm{z}$ dodatkiem samego fungicydu $\mathrm{w}$ dawce $\mathrm{A}$, a także Dithane Neo Tec 75 WG łącznie z wyciąiem glebowym I. Fungicyd Dithane Neo Tec 75 WG dodany do podłoża w dawce 10-krotnie niższej od zalecanej (B) o ponad 50\% ograniczył wzrost kolonii $M$. anisopliae w stosunku do kontroli.

Wprowadzenie do podłoża zarówno wyciągu glebowego I, jak i II spowodowało dodatkowe zahamowanie wzrostu kolonii. Wielkość kolonii grzyba w 20 dniu obserwacji wyniosła odpowiednio 36,9 oraz $29,3 \%$ w stosunku do kontroli, natomiast na podłożu $\mathrm{Z}$ samym fungicydem w dawce B - 45,1\%. Dithane Neo Tec 75 WG dodany do podłoża $w$ dawce 100-krotnie niższej od zalecanej dawki polowej (C) nie wpływał negatywnie na wzrost $M$. anisopliae, jednak dodatek wyciągów glebowych wpływał nieznacznie na zahamowanie jego rozwoju (tab. 1, rys. 2).

Antracol 70 WG wykazał najmniej toksyczne działanie w stosunku do M. anisopliae spośród badanych fungicydów. Kolonie grzyba na podłożu zawierającym ten preparat $\mathrm{z}$ dodatkiem wyciągów, a także bez nich, osiągnęły największe rozmiary (tab. 1, rys. 3). Preparat dodany do podłoży w zalecanej dawce polowej (A), o około $43 \%$ ograniczył wzrost kolonii $M$. anisopliae w stosunku do kontroli. Antracol $70 \mathrm{WG}$ w dawce 10-krotnie niższej od zalecanej (B), w mniejszym stopniu hamował wzrost $M$. anisopliae, niż w stężeniu A. Kolonie grzyba na pożywce $\mathrm{z}$ tą dawką fungicydu w 20 dniu obserwacji osiągnęły 84,5\% wielkości kultur kontrolnych. Dodatek pierwszego wyciagu glebowego dodatkowo hamował wzrost grzyba, którego kolonie w 20 dniu osiągnęły 69,5\% wzrostu kultur rosnących na czystych podłożach hodowlanych. Jeszcze większy inhibicyjny wpływ na wzrost $M$. anisopliae miał dodatek do podłoża $\mathrm{z}$ fungicydem drugiego wyciągu glebowego. Kolonie grzyba na tym podłożu osiągnęły jedynie 56,7\% wzrostu kolonii kontrolnych.

Antracol 70 WG dodany do podłoży hodowlanych W stężeniu 100-krotnie niższym od zalecanej dawki polowej (C), nie wpływał w sposób istotny na wzrost grzyba. Zaobserwowano nawet lekką stymulację wzrostu kolonii (118,0\% wielkości kolonii kontrolnych).

Testowane w doświadczeniu fungicydy wpływały w zróżnicowany sposób na wzrost grzyba $M$. anisopliae w zależności od rodzaju preparatu oraz jego koncentracji w podłożu hodowlanym. Najsilniej wzrost patogena hamował preparat Score $250 \mathrm{EC}$, a stosunkowo najsłabiej Antracol $70 \mathrm{WG}$, co może wskazywać na możliwość łącznego stosowania tego ostatniego fungicydu (zwłaszcza w obniżonych dawkach) wraz z $M$. anisopliae w integrowanych programach ochrony roślin (IPM - Integrated Pest Management). 
Na silny inhibicyjny wpływ niektórych fungicydów na grzyby owadobójcze w warunkach in vitro wskazują badania wielu autorów. Według Li i Holdom (1994) izolaty $M$. anisopliae wykazywały większą tolerancję na środki owadobójcze i herbicydy niż na fungicydy. Podobne wyniki odnotowali Loureiro i wsp. (2002), którzy zaobserwowali, że wzrost $M$. anisopliae był najsilniej hamowany przez środki grzybobójcze.
Andalo i wsp. (2004), Li i wsp. (2004) oraz Tkaczuk i wsp. (2012) stwierdzili stosunkowo małą szkodliwość insektycydów i średni inhibicyjny wpływ herbicydów na wzrost grzybów owadobójczych $\mathrm{w}$ warunkach in vitro. Najbardziej negatywnie na te mikroorganizmy wpływały fungicydy, a ich oddziaływanie w dużym stopniu uzależnione było od substancji czynnej, koncentracji w podłożu oraz gatunku grzyba.

Tabela 1. Wielkość kolonii grzyba M. anisopliae na pożywkach z fungicydami oraz wyciagami glebowymi (wyrażona w \% w stosunku do kontroli)

Table 1. Colony size of the fungus M. anisopliae on media with fungicides and soil extracts (expressed as \% relative to control)

\begin{tabular}{|c|c|c|c|c|c|c|c|c|c|c|}
\hline \multirow{3}{*}{ 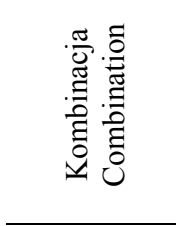 } & \multirow{3}{*}{ 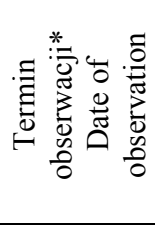 } & \multicolumn{9}{|c|}{ Nazwa fungicydu - Fungicide } \\
\hline & & \multicolumn{3}{|c|}{ Antracol $70 \mathrm{WG}$} & \multicolumn{3}{|c|}{ Dithane Neo Tec 75 WG } & \multicolumn{3}{|c|}{ Score $250 \mathrm{EC}$} \\
\hline & & A & B & $\mathrm{C}$ & A & B & $\mathrm{C}$ & A & $\mathrm{B}$ & $\mathrm{C}$ \\
\hline \multirow{3}{*}{$\begin{array}{l}\text { Fungicyd } \\
\text { bez wyciagu } \\
\text { Fungicide } \\
\text { without soil } \\
\text { extract }\end{array}$} & 5 & $36,7 \pm 4,5$ & $54,7 \pm 5,5$ & $96,9 \pm 4,3$ & $23,4 \pm 0,0$ & $35,2 \pm 4,5$ & $21,9 \pm 6,5$ & BW & BW & $46,9 \pm 0,0$ \\
\hline & 10 & $45,2 \pm 9,1$ & $63,2 \pm 3,9$ & $104,4 \pm 4,4$ & $15,4 \pm 4,4$ & $37,3 \pm 5,1$ & $81,6 \pm 3,9$ & BW & $23,2 \pm 4,4$ & $50,0 \pm 5,0$ \\
\hline & 15 & $56,7 \pm 4,9$ & $78,2 \pm 4,3$ & $114,7 \pm 2,6$ & $16,7 \pm 6,6$ & $40,1 \pm 3,2$ & $99,4 \pm 3,2$ & BW & $37,8 \pm 6,6$ & $58,3 \pm 2,1$ \\
\hline \multirow{3}{*}{$\begin{array}{l}\text { Fungicyd } \\
+ \text { wyciag I } \\
\text { Fungicide } \\
\text { with } \\
\text { extract I }\end{array}$} & 5 & $32,9 \pm 4,0$ & $38,6 \pm 9,6$ & $68,6 \pm 6,4$ & $21,4 \pm 0,0$ & $26,4 \pm 4,2$ & $55,7 \pm 7,8$ & BW & SW & $47,1 \pm 3,6$ \\
\hline & 10 & $43,7 \pm 7,0$ & $53,8 \pm 4,6$ & $87,4 \pm 3,5$ & $14,7 \pm 3,0$ & $26,5 \pm 2,4$ & $74,8 \pm 4,6$ & BW & $20,2 \pm 6,3$ & $50,4 \pm 4,2$ \\
\hline & 15 & $47,3 \pm 5,1$ & $63,6 \pm 2,2$ & $94,5 \pm 2,9$ & $13,6 \pm 6,4$ & $30,3 \pm 8,0$ & $86,7 \pm 7,8$ & BW & $39,4 \pm 8,4$ & $60,6 \pm 3,7$ \\
\hline \multirow{3}{*}{$\begin{array}{l}\text { Fungicyd + } \\
\text { wyciag II } \\
\text { Fungicide } \\
\text { with } \\
\text { extract II }\end{array}$} & 5 & $32,3 \pm 5,7$ & $48,4 \pm 0,0$ & $77,4 \pm 6,8$ & SW & $32,3 \pm 0,0$ & $66,1 \pm 6,7$ & BW & $40,3 \pm 11,4$ & $50,0 \pm 3,6$ \\
\hline & 10 & $48,6 \pm 7,4$ & $57,7 \pm 3,8$ & $78,4 \pm 4,5$ & $13,5 \pm 0,0$ & $30,2 \pm 2,6$ & $75,7 \pm 3,8$ & BW & $30,6 \pm 9,4$ & $57,7 \pm 2,0$ \\
\hline & 15 & $60,7 \pm 2,3$ & $60,1 \pm 1,4$ & $85,6 \pm 3,0$ & $9,6 \pm 0,0$ & $32,9 \pm 2,0$ & $89,5 \pm 0,1$ & BW & $46,6 \pm 4,5$ & $69,0 \pm 2,9$ \\
\hline
\end{tabular}

A - zalecana dawka fungicydu - recommended fungicide dose

$\mathrm{B}$ - dawka 10-krotnie niższa od zalecanej dawki - dose 10 times lower than recommended

$\mathrm{C}$ - dawka 100-krotnie niższa od zalecanej-dose 100 times lower than recommended

BW - brak wzrostu - no growth; SW - ślady wzrostu - signs of growth

*Termin obserwacji (w dniach) - Date of obserwation (in days)

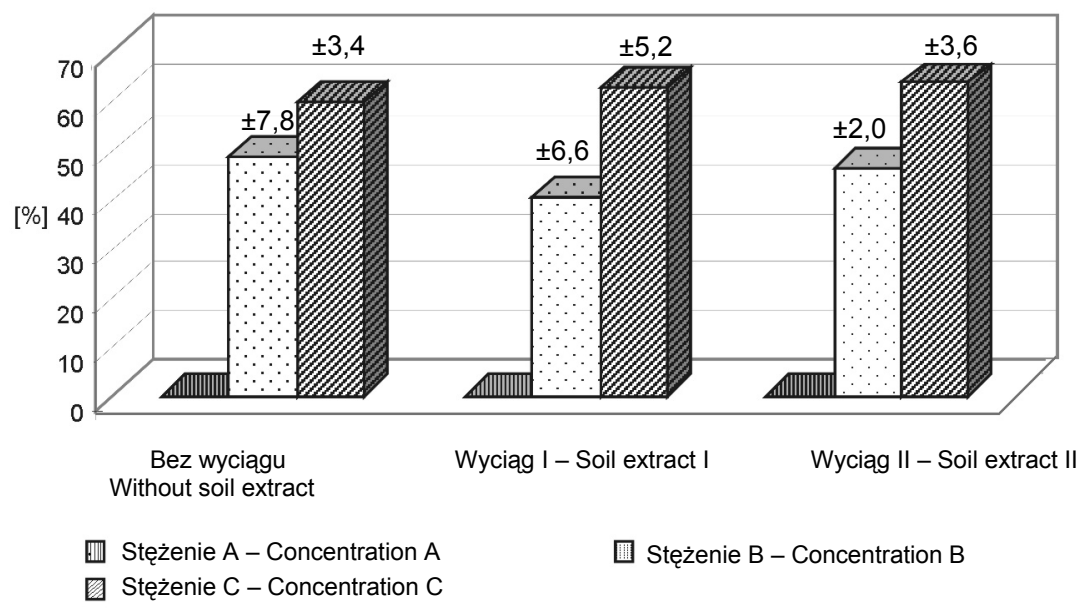

Rys. 1. Wielkość kolonii M. anisopliae w 20. dniu hodowli na podłożach z dodatkiem fungicydu Score 250 EC i wyciaggów glebowych (wyrażona $\mathrm{w} \% \mathrm{w}$ stosunku do kontroli)

Fig. 1. M. anisopliae colony size after 20 days of incubation on media supplemented with fungicide Score 250 EC and soil extracts (expressed as \% relative to control) 


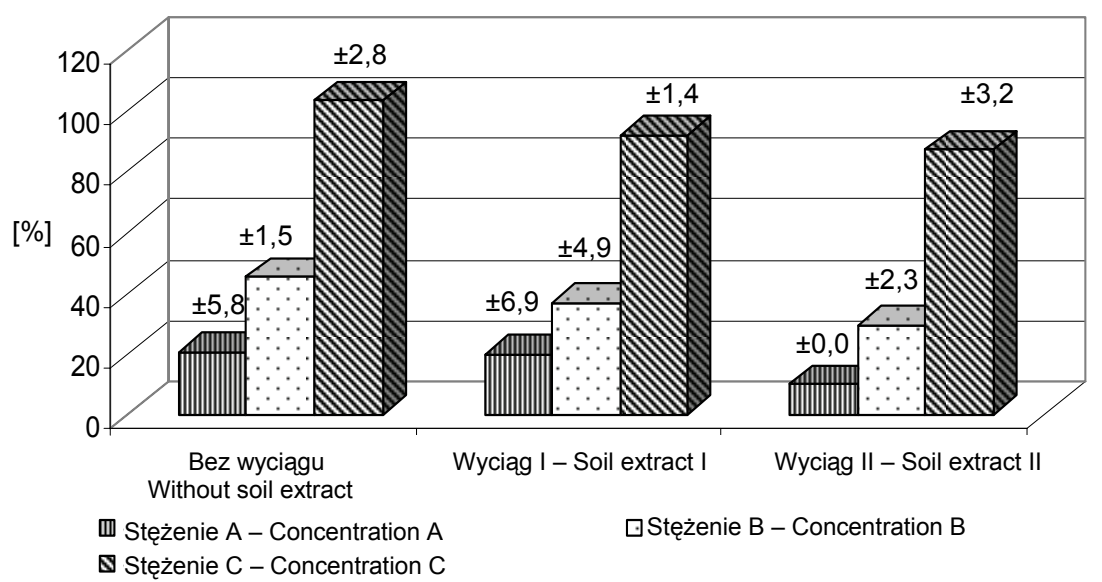

Rys. 2. Wielkość kolonii M. anisopliae w 20. dniu hodowli na podłożach z dodatkiem fungicydu Dithane Neo Tec 75 WG i wyciagów glebowych (wyrażona w \% w stosunku do kontroli)

Fig. 2. M. anisopliae colony size after 20 days of incubation on media supplemented with fungicide Dithane Neo Tec 75 WG and soil extracts (expressed as \% relative to control)

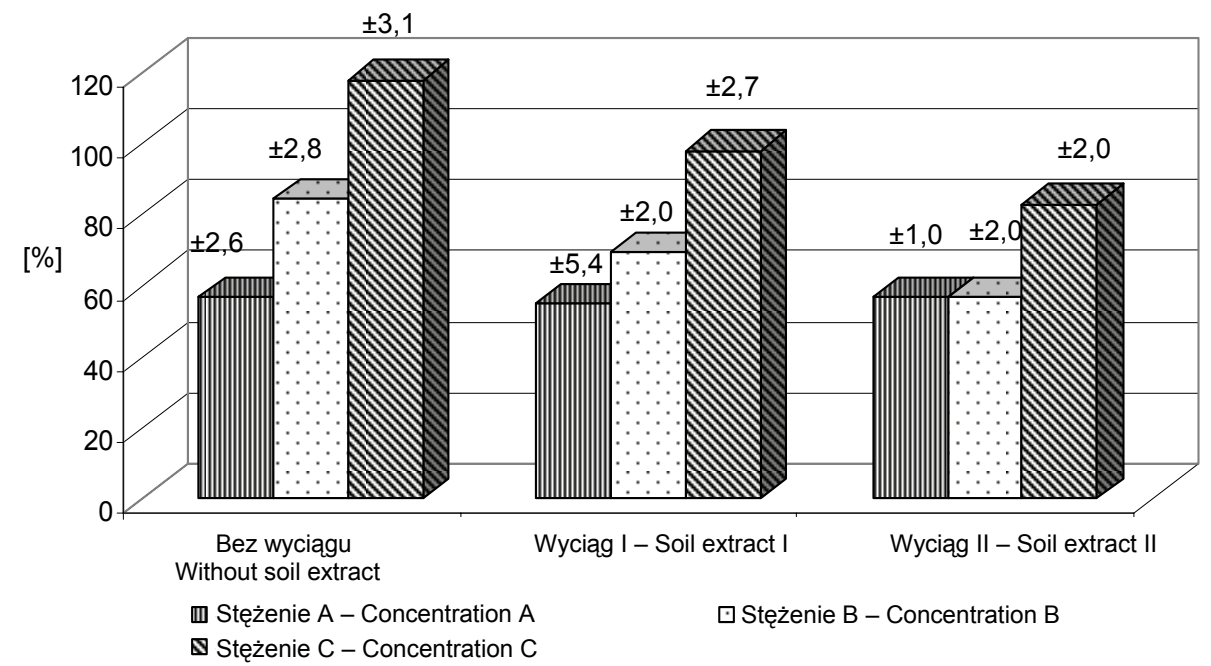

Rys. 3. Wielkość kolonii M. anisopliae w 20. dniu hodowli na podłożach z dodatkiem fungicydu Antracol 70 WG i wyciagów glebowych (wyrażona w \% w stosunku do kontroli)

Fig. 3. M. anisopliae colony size after 20 days of incubation on media supplemented with fungicide Antracol $70 \mathrm{WG}$ and soil extracts (expressed as \% relative to control)

Uzyskane w pracy wyniki wyraźnie wskazują, że dodanie do podłoża hodowlanego $\mathrm{z}$ fungicydami wyciągów glebowych wpływało inhibicyjnie na wzrost badanego grzyba. Wyciąg z gleby organicznej dodany do podłoża hodowlanego $\mathrm{z}$ fungicydami silniej hamował wzrost M. anisopliae niż wyciąg otrzymany z gleby piaszczystej. Dokładne wytłumaczenie przyczyn tego zjawiska wymagałoby przeprowadzenia dodatkowych, szczegółowych badań dotyczących interakcji w układzie fungicyd-roztwór glebowy-grzyb. Należy jednak pamiętać, że trwałość oddziaływań syntetycznych fungicydów organicznych $\mathrm{w}$ środowisku glebowym i tempo ich degradacji uzależniona jest od wielu czynników abiotycznych i biotycznych. Dostępność i trwałość fungicydów w środowisku glebowym jest związana $\mathrm{z}$ rodzajem i skalą procesów ich adsorpcji i desorpcji, obejmujących zespół złożonych oddziaływań chemicznych z fazą mineralną i organiczną gleby. Chociaż charakter przebiegu tych procesów nie jest do końca poznany to uważa się, że za adsorpcję fungicydów organicznych $w$ glebie są odpowiedzialne składniki frakcji organicznej gleby, tlenki oraz minerały gliniaste (Gevao i wsp. 2000; Komarek i wsp. 2010). Można więc przypuszczać, że dodanie roztworów glebowych do podłoży hodowlanych zawierających fungicydy mogło wpłynąc na zwiększenie stopnia ich związania $\mathrm{z}$ substancjami organicznymi gleby, a tym samym przedłużyć okres ich toksycznego oddziaływania na grzyba.

Przeprowadzone w pracy eksperymenty laboratoryjne, $\mathrm{z}$ zastosowaniem wysterylizowanego roztworu glebowego, $\mathrm{z}$ pewnością nie dają pełnego obrazu interakcji zachodzących pomiędzy grzybami owadobójczymi i fungicydami, które w warunkach naturalnych mogą być modyfikowane przez szereg czynników biotycznych. Wśród nich na szczególną uwagę zasługują antagonistyczne i synergi- 
styczne oddziaływania innych mikroorganizmów obecnych w środowisku glebowym, zwłaszcza bakterii i grzybów, które mogą wpływać zarówno na aktywność biologiczną grzybów owadobójczych, jak i samych fungicydów (Lingg i Donaldson 1981; Hajek 1997; Shimazu i wsp. 2002).

\section{Wnioski / Conclusions}

1. Spośród badanych fungicydów najsilniej wzrost owadobójczego grzyba $M$. anisopliae hamował preparat Score 250 EC, a stosunkowo najsłabiej Antracol 70 WG.
2. Dodanie do podłoża hodowlanego z fungicydami wyciągów glebowych wpływało inhibicyjnie na wzrost grzyba.

3. Stopień ograniczenia wzrostu grzyba na pożywkach z fungicydami i wyciągami był uzależniony od pochodzenia wyciągów glebowych. Wyciąg z gleby organicznej dodany do podłoża hodowlanego z fungicydami silniej hamował wzrost $M$. anisopliae niż wyciąg sporządzony z gleby piaszczystej.

\section{Literatura / References}

Andalo V., Moino A., Santa-Cecilia L.V.S., Souza G.C. 2004. Compatibility of Beauveria bassiana with chemical pesticides for the control of the coffee root mealybug Dysmicoccus texensis Tinsley (Hemiptera: Pseudococcidae). Neotrop. Entomol. 33: $463-467$.

Bajan C., Kmitowa K. 1997. Thirty years studies of nine fungicides on growth of entomopatogenic fungi in the Institute of Ecology PAS. Pol. Ecol. Stud. 23 (3-4): 133-154.

Boucias D.G., Pendland J.C., Latage J.P. 1988. Nonspecific factors involved in attachment of entomopathogenic deutromycetes to host insect cuticle. Appl. Environ. Microbiol. 54: 1795-1805.

Das A.C., Chakravarty A., Sen G., Sukul P., Mukherjee D. 2005. A cooperative study on the dissipation and microbial metabolism of organophosphate and carbamate insecticides in orchaqualf and fluvaquent soils of West Bengal. Chemosphere 58: 579-584.

Ferron P. 1981. Pest control by the fungi Beauveria and Metarhizium. p. 465-482. In: "Microbial Control of Pest and Plant Diseases", 1970-1980 (H.D. Burges, ed.). Academic Press, London, 949 pp.

Fiedler Ż., Sosnowska D. 2011. Wpływ wybranych fungicydów na wzrost i zarodnikowanie grzybów owadobójczych. [The influence of fungicides on the growth and sporulation of entomopathogenic fungi]. Prog. Plant Prot./Post. Ochr. Roślin 51 (2): 911-915.

Gevao B., Semple K.T., Jones K.C. 2000. Bond pesticide residues in soils: a review. Environ. Pollut. 108: 3-14.

Hajek A.E. 1997. Ecology of terrestrial fungal entomopathogens. Adv. Microb. Ecol. 15: 193-249.

Ignoffo C.M., Garcia C., Hostetter D.L., Pinnell R.E. 1978. Stability of conidia of an entomopathogenic fungus, Nomuraea rileyi, in and on soil. Environ. Entomol. 7: 724-727.

Komarek M., Cadkova E., Chrastny V., Bordas F., Bollinger J.-C. 2010. Contamination of vineyard soils with fungicides: A review of environmental and toxicological aspects. Environ. Int. 36: 138-151.

Krysa A., Ropek D., Kuźniar T. 2012. Występowanie grzybów owadobójczych w zależności od pory roku w wybranym ekologicznym gospodarstwie rolnym. J. Res. Appl. Agric. Engin. 57 (3): 226-230.

Li D.P., Holdom D.G. 1994. Effects of pesticides on growth and sporulation of Metarhizium anisopliae (Deuteromycotina: Hyphomycetes). J. Invert. Pathol. 63: 209-211.

Li W., Fang X.F., Sheng C.F. 2004. Impact of sixteen chemical pesticides on conidial germination of two entomophthoralean fungi: Conidiobolus thromboides and Pandora nouryi. Biocontr. Sci. Technol. 14: 737-741.

Lingg A.J., Donaldson M.D. 1981. Biotic and abiotic factors affecting stability of Beauveria bassiana conidia in soil. J. Invert. Pathol. 38: $191-200$

Loureiro E.S., Moino Jr. A., Arnosti A., Souza G.C. 2002. Effect of chemical products used in lettuce and chrysanthemum on entomopathogenic fungi. Neotrop. Entomol. 31: 263-269.

Majchrowicz I., Poprawski T.J. 1993. Effects in vitro of nine fungicides on growth of entomopathogenic fungi. Biocontrol. Sci. Technol. 3: 321-336.

Megharaj M., Kantachote D., Singelton I., Naidu R. 2000. Effect of long-term contamination of DDT on soil microflora with special references to soil algae and algae transformation DDT. Environ. Pollut. 109: 35-42.

Miętkiewski R.T., Pell J.K., Clark S.J. 1997. Influence of pesticides use on the natural occurrence of entomopathogenic fungi in arable soils in UK: Field and laboratory comparisons. Biocontrol. Sci. Technol. 7: 565-575.

Mochi D.A., Monteiro A.C., Bartosa J.C. 2005. Action of pesticides to Metarhizium anisopliae in soil. Neotrop. Entomol. 34 (6): 961-971.

Prior C., Greathead D.J. 1989. Biological control of locusts: the potential for the exploitation of patohogens. FAO Plant Prot. Bull. 37: 37-48.

Shimazu M., Maehara N., Sato H. 2002. Density dynamics of the entomopathogenic fungus, Beauveria bassiana Vuilemin (Deuteromycotina: Hyphomycetes) introduced into forest soil, and its influence on other soil microorganisms. Appl. Entomol. Zool. 37: 263-269.

Tkaczuk C., Krzyczkowski T., Głuszczak B., Król A. 2012. Wpływ wybranych środków ochrony roślin na wzrost kolonii i kiełkowanie zarodników owadobójczego grzyba Beauveria bassiana (Bals.) Vuill. [The influence of selected pesticides on the colony growth and conidial germination of the entomopathogenic fungus Beauveria bassiana (Bals.) Vuill.]. Prog. Plant Prot./Post. Ochr. Roślin 52 (4): 969-974.

Tkaczuk C. 2001. Wpływ wybranych pestycydów stosowanych w ochronie sadów na wzrost grzybów owadobójczych. Biul. Nauk. 12: $375-383$

Tkaczuk C. 2008. Występowanie i potencjał infekcyjny grzybów owadobójczych w glebach agrocenoz i środowisk seminaturalnych w krajobrazie rolniczym. Rozprawa Naukowa 94, Wyd. Akademii Podlaskiej, 160 ss.

Vänninen I., Tyni-Juslin J., Hokkanen H.M.T. 2000. Presistance of augmented Metarhizium anisopliae and Beauveria bassiana in Finnish agricultural soils. Biocontrol 45: 201-222. 